\title{
Reflexive Game in the Work with Students from Post-conflict Regions
}

\author{
Karine A. Babiyants* (a), Olga V. Manuylova (b) \\ (a), (b) South Federal University, 344038, Rostov-on-Don (Russia), 13 M.Nagibina street, \\ bakart@sfedu.ru
}

\begin{abstract}
In modern psychological and pedagogical practice reflective and transformational games are actively used as preventive educational measures. We developed a reflexive game with the goal of creating conditions for individual development of the reflective potential of students in the process of interpersonal interaction, identifying cultural attitudes and minimizing mythological stereotypes, formation of ability to resist to psychological pressure and to critically assess any conflict situations.

The aim of our study was to examine the influence of the reflexive games on the increase of the perceived ability of students to analyze the course of events in situations of an extremist nature.

The main methods used were monitoring, testing, and statistical methods of processing of quantitative data. The study involved 32 students from the conflict region (Lugansk National Institute named by V. Dahl), 35 students from the border region (Southern Federal University), and 30 students from the post-conflict region (Chechen State Pedagogical University).

In the study, it was discovered that a reflexive game allows to find the balance between awareness of the past, present, and future events; to promote reflexive thinking in the collective solution of tasks; to reduce the non-adaptive state of individual personality development and to increase social adaptability to such polarities as aggressiveness-anxiety, spontaneity-sensitivity, extraversion-introversion; to reduce the emotional anxiety in a situation of experiencing frustration.

The studied patterns can be used in intercultural and integrative approaches by specialists of different levels working with students.
\end{abstract}

Keywords: reflection, reflective game, extremism, students, frustration, conflict region, post-conflict region.

(C) 2020 Karine A.Babiyants, Olga V.Manuylova

This is an open access article distributed under the terms of the Creative Commons Attribution License (CC BY 4.0), which permits unrestricted use, distribution, and reproduction in any medium, provided the original author and source are credited.

Published by Kazan federal university and peer-reviewed under responsibility of IFTE-2020 (VI International Forum on Teacher Education) 


\section{Introduction}

In psychological and pedagogical practice, reflexive and transformational games have become a popular area of research on various sensitive issues in the youth environment, such as suicidal behavior, the spread of AIDS and HIV infection, the prevention of youth extremism, and involvement in antisocial groups. Game technologies are successfully applied in pedagogical activity as preventive educational measures.

The relevance of the study is justified by the specifics of the conditions of hostilities in conflict regions, in post-conflict and border regions, where the sensitivity to manifestations of youth extremism is especially acute. Extremism is a complex socio-political phenomenon that has a tendency to develop, which is due to the presence of a number of socio-economic and cultural factors that closely interact with each other (Znakov, \& Turok, 2010). The contradictions are especially acute in those regions where the population has a multinational structure, represented by various ethnic and religious groups. Such areas include the South of Russia, the North Caucasus, the young people's republics of Chechnya, Lugansk and Donetsk regions (Krotov, 2009; Khadzharov, 2011).

The creation and testing of the original "Reflective Game" procedure is a fairly new approach that contributes not only to the development of reflection among university students, but also forms resistance to involvement in extremist activities, reduces emotional frustration in the situation of extremism in the youth environment, especially among students living in conflict and post-conflict regions. An important aspect, in our opinion, is the possibility of implementing in the reflexive game the relationship between different types of reflection and the reflective and innovative potential of the personality, which should form an understanding of the personal and behavioral aspects in situations of manifestation of extremism in the youth environment, an understanding of possible personal reactions, reactions significant and insignificant others involved in the same situation. A creative and regulatory type of reflection may develop, associated with the awareness and rethinking of stereotypes of planning and organizing one's own activity in a situation of emotional frustration.

\section{Purpose and objectives of the study}

The aim of the study was to test empirically the influence of reflective games on changes in the severity of reflection and emotional response in a situation of frustration among students from regions with different post-conflict status. 


\section{Literature review}

Using reflective gaming technology in the prevention of extremism in the youth environment, we turn to the meaningful and semantic structures of creative thinking to develop operational, substantive reflective and personal components. In conditions of hostilities in conflict regions, in post-conflict and border regions, there is an especially acute susceptibility to the manifestations of youth extremism (Babiyants, 2011; Manuylova, 2015). "Action, deed, crime is called extremist, which has in its basis an ideological base" (Sikevich, 2003, p. 124). One of the forms of extremism as behavior that deviates from social and legal norms is the use of methods of moral and psychological pressure. This trend is due to a growing disregard for the rules and norms of behavior in society, the denial of the existing social order as ineffective, the development of "abnormal" attitudes in the group consciousness of the young generation, the negative transformation of values and preferred behaviors. In a broad sense, the growth of youth extremism is associated with the social and political culture of Russian society in its projective consciousness (Abakumova \& Ermakova, 2013).

The use of reflection as a preventive anti-extremist activity drew us to understanding the types of reflection as a General psychological phenomenon. Researchers Semenov (2005) and Stepanov (2000) consider intellectual, personal and communicative reflection. Researchers Karpov and Ponomareva (2000) studied the reflection in relation to the time perspectives. Leontiev and Averina (2011) looked into the open reflection in the context of self-regulation.

In this study, we rely on the ideas of modern psychology of thinking about the conditions for subjects to understand the system of their own actions and their foundations (Tulviste, 1984; Grant, 2001; Lefebvre, 2003; Semenov, Davydov, \& Boldina, 2003; Rubinstein, 2003; Beitel, Ferrer, \& Cecero, 2004; Pyankova, 2012); on the conditions of reflexive self-regulation of the creative process, as a result of which the subject is rethinking his thought activity (Ponomarev, Semenov, \& Stepanov, 1986; Karpov \& Skityaeva, 2005; Semenov, 2005).

Research on reflection in university students living in regions of Russia with different post-conflict status is a relevant and almost unexplored area, which, however, is based on well-known socio-psychological laws. These include an understanding of reflection as a model of mutual reflection and the possibility of "reproducing each other" (Lefebvre, 2003; Pyankova, 2012); understanding of reflection as the knowledge of the subject about himself, and as the content of others ideas about the reflecting subject in the context of joint activity, in communication, in dyadic relationships (Langer, 1978; Fenigstein, 1997; Stepanov, 2000; Semenov, 2005; Usheva, 2007). 
Based on the above provisions, the relevance of the development and use of reflective games as pedagogical technology for the formation of awareness, self-regulation and adaptation among students in regions with different post-conflict status becomes apparent.

\section{Methodology}

Empirical research and testing of reflexive games were carried out in higher education institutions: Lugansk National Institute named after V. Dalya, Southern Federal University, Chechen State Pedagogical University. The study involved students in the amount of 97 people.

The following diagnostic tools were used in the study:

- test "Individual typological questionnaire" by Sobchik (2017), in order to identify individual typological characteristics of students and trends in social interaction;

- test "Determining the level of reflexivity" by Karpov and Ponomareva (2000) in order to identify reflection on the temporal perspective: situational, retrospective, perspective, as well as the reflection of interaction;

- modified test by Anisimov (1996), “The Definition of Reflexivity of Thinking," with the goal of monitoring changes in group reflection in collaboration;

- "A projective methodology to eliminate the causes and facts of the growth of ethno-confessional extremism for individual subjects" by Babiyants (2011), with the aim of studying the response in a situation of frustration among university students;

- statistical methods for processing the results: Conover's two - sample squared ranks test for equality of variance; Kraskel-Wallis test; Spearman rank correlation.

\section{Description and methods of reflexive game}

The time for the reflexive game from 2 to 2.5 hours. Number of participants: from 10 to 30 people. Before and after the reflexive game, reflexivity and emotional response to frustration were monitored. Preliminary diagnostics of individually-typological and reflective characteristics of students participating in a reflective game was carried out.

Handout material was used: cards with projective materials, tables with the type of reactions for each participant, means for drawing and presentation for each group. 


\section{Stages and content of a reflective game}

Stage 1: participants are divided into groups. The principle of separation is formed during the game.

Stage 2: acquaintance with situations and definitions of extremism. Each individual task is given to pass the projective test.

Stage 3: acquaintance with reaction types; self-reflection. Each participant is invited to attribute their response to a specific type of reaction and then calculate which reactions dominate within the group.

Stage 4: it is proposed to demonstrate the results of quantitative calculation during group work on the dominant type of reaction, to select a representative from the group to present the most optimal group decision during an interactive exchange of views.

Stage5: presentation of the group's decision, justification of its position - why this decision will be most acceptable in this situation; intergroup discussion.

Stage 6: the general conclusion on the intergroup discussion is which type of behavior is the most optimal in the current situation in order to avoid involvement in an extremist group.

Stage 7: acquaintance with the recommendations of the Ministry of Emergency Situations and the Federal Security Service of Russia on how to behave in a situation of threat of extremist manifestations.

\section{Results}

We have selected students to participate in a reflective game. The principle for selection was indicators of low reflection of thinking, pronounced accentuation of individual typological properties and high emotional frustration in a situation of extremism. The severity of reflection and emotional frustration was monitored before and after the reflexive game. The monitoring was based on the three most indicative methods enumerated in the methodology section.

The difference in the indicator "aggravation" (underlining problems) was reliably confirmed in three samples of subjects (Kruskal-Wallis chi-squared $=9.5516, \mathrm{df}=2, \mathrm{p}$-value $=0.008431$ ). At the same time, according to the Conover criterion, the students of the conflict region (9.3e-05), then the post-conflict region (3.9e-05), and the highest rate among students of the border region are the most reliable.

Significantly different result in terms of "Social desirability" (Kruskal-Wallis chi-squared $=19.546$, df $=2$, p-value $=5.698 \mathrm{e}-05)$. The highest rate was reliably expressed among students of the post-conflict region 
compared with the border region ( $9.3 \mathrm{e}-05$ by the Conover criterion), and compared with the conflict region (3.9e-05 by the Conover criterion). We are inclined to consider these differences from the point of view of ethno-confessional and cultural attitudes of students in this region.

Another striking indicator was the property "Spontaneity". According to the Kruskal-Wallis criterion (Kruskal-Wallis chi-squared $=7.5393, \mathrm{df}=2, \mathrm{p}$-value $=0.02306$ ), "spontaneity" was reliably most highly expressed among students of the border region. Moreover, according to the Conover criterion, students of the post-conflict region "spontaneity" are much lower than students of the border region $(0.0058)$. This indicates the severity of extravert-active, spontaneous behavior among students of the border region who seek independence and leadership, show high conflict and aggressiveness. Such an indicator as "Extraversion" is most pronounced among students in the conflict than in students in the post-conflict zone (0.02), and "Anxiety" is more characteristic of students in the conflict region (0.031) compared to the other two according to the Conover criterion. Such data analysis is extremely relevant for understanding the style of interpersonal behavior, which is directly dependent on the type of response to emotional frustration. Anxious introverted students are distinguished by the need to maintain a warm relationship with a small, but especially significant social circle and a dependent position on the leader in the reference group. And we see confirmation of this in a comparison of students' indicators with alarming introversion and a pronounced reaction in a situation of emotional frustration, with the fixation on the problem. At the same time, rigid, introverted-individualistic and pedantic students are characterized by hard modifiable behavior that often leads to conflict with the environment or the care of the contacts and then we have the type of reaction related either with the fixation on self-defense with the attack on the source of frustration, or escape from the current situation and fixing on the type of reaction when the problem is graded as a minor or as not existing. In total, we have two major trends: on the one hand, forces directed outward (the offensive activity, opposition, aggression against the source of frustration), or, on the contrary, the trends aimed at themselves (self-blame, anxiety, refusal to implement their own plans).

In total, we have two leading trends: on the one hand, forces directed outward (offensive activity, resistance, aggression against the source of frustration), or, on the contrary, trends aimed at oneself (selfincrimination, anxiety, refusal to implement our own plans)

Such conclusions are confirmed by Spearman's statistical correlation analysis. It was proved that the indicator "Social desirability" among students of all groups negatively correlates with the level of reflexivity in the collective solution of the problem $(-0.26$, with $\mathrm{p}=0.03)$. With a high "social desirability", students have a low level of reflectivity (which is expressed among students of post-conflict and border regions), and, on the contrary, low "social desirability" is interconnected with an adequate level of 
reflection (which is expressed among students of a conflict region). There is also a positive relationship between "Aggression" and the level of collective reflexivity $(0.24$, at $\mathrm{p}=0.04)$. "Extraversion" correlates with the average level of reflexivity in the collective solution of the problem $(0.25$, at $p=0.03)$. Those students from different regions who have the greatest extroversion and outward orientation are more easily involved in solving collective problems. "Emotional lability" also positively correlates with the level of collective reflexivity $(0.26$, at $\mathrm{p}=0.03)$. Reactions, mainly aimed at oneself, inside the person, determine social behavior and the type of reaction in a situation of emotional frustration. Thus, introversion negatively correlates with reflexivity in solving group problems $(-0.27$, with $p=0.02)$, and the level of collectivity $(-0.44$, with $\mathrm{p}=0.00)$.

As a result of the monitoring before and after the reflexive game, we found a fairly clear alignment of the positions of reflexivity in all three groups of subjects. So, in the group of students in the conflict region, we see a significant increase in indicators of reflection, aimed at present events and sociability, a decrease in indicators of retrospective reflection and focus on the future, which in general makes it possible to balance the balance between all types of reflection. Students of the post-conflict region have decreased indicators of present reflection and increased focus on the future and reflection of communication, while students in the border region have leveled off balance by increasing reflection on the future and interpersonal interaction (Figure 1).

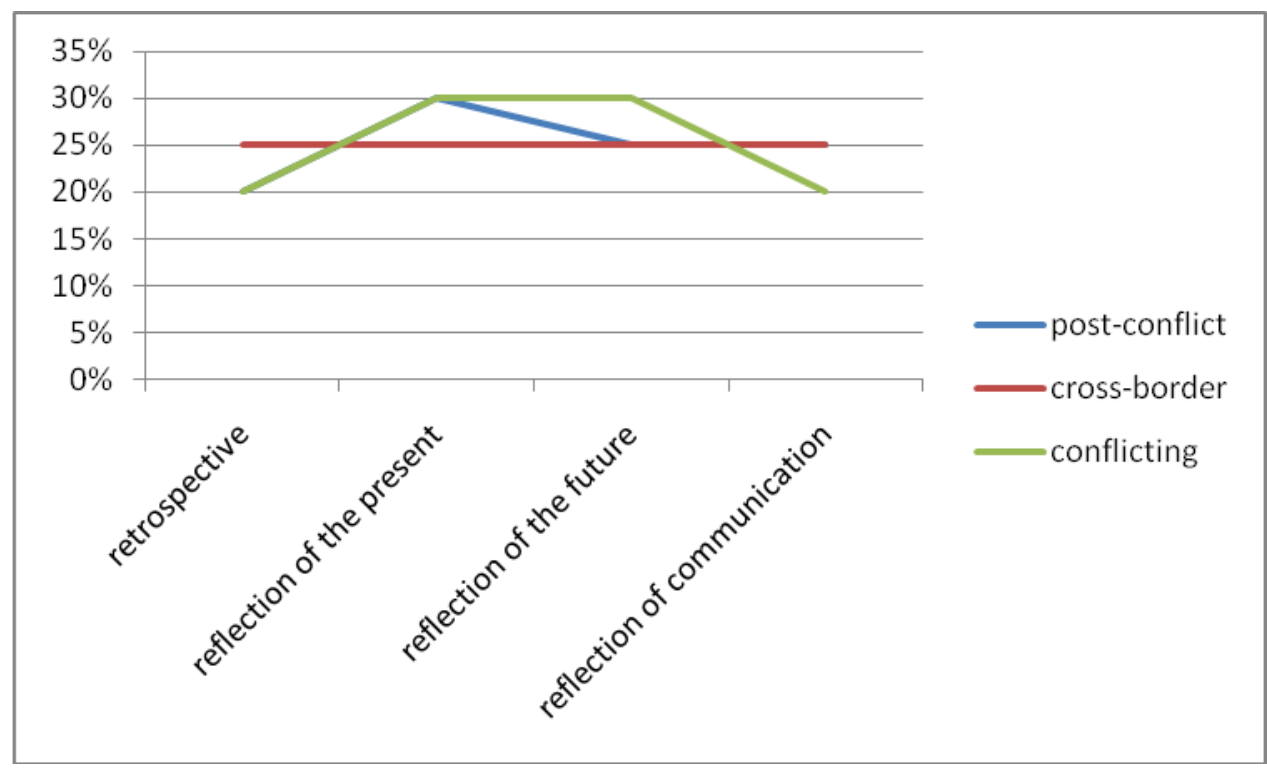

Figure 1. The distribution of the balance between the types of reflection in students of conflict, postconflict and border regions after the reflexive game 
During the monitoring after the reflexive game, the indicators of all groups of students in group reflection also changed significantly (Figure 2).

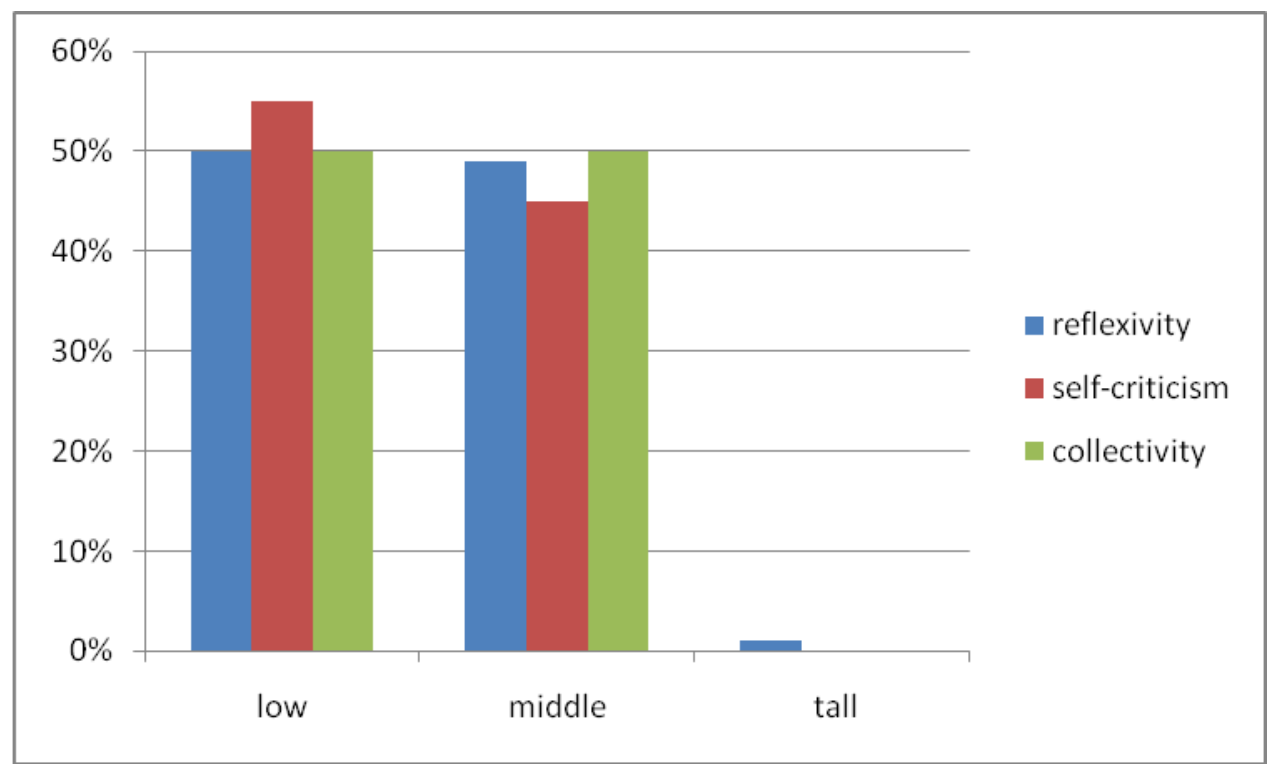

Figure 2. Average indicators for all groups of subjects regarding the reflexivity of thinking when working together

The "Reflexivity" of thinking significantly increased, the low level decreased to $50 \%$, the average level of "Reflexivity" increased to $45 \%$ and a $1 \%$ high "Reflexivity" appeared. We regard this as the development of the ability to turn to the analysis of the solution of a problem, to analyze unsuccessful attempts to solve, to search for the causes of inadequate solutions and to increase the general level of "Reflexivity" of thinking in collective work.

The "Self-criticality" indicator in all groups of subjects increased to an average level (in $45 \%$ of cases), which is a significant increase in the awareness of one's own behavior, strategies and tactics for solving problems, and moves students towards critical thinking with respect to themselves. The indicator "Collective" thinking when working together has also increased to 50\%, indicating the tendency to listen to the opinions of others, to check their point of view, to compare their and others ' positions relative to the overall achievement of the outcome. 
During monitoring of the reflexive game, significant changes were recorded in the emotional response to frustration in all three groups of tested students, regardless of post-conflict status, cultural and ethnoconfessional attitudes.

The most adequate (constructive) type of response appears in situations of involvement in an extremist group, manifestations of extremism in the youth environment. The constructive type of response to emotional frustration is characterized by a high reflection of the situation and one's position, a tendency to assess the behavior of people on both sides of the conflict, accompanied by included attention and increased observation.

During the reflective game, the students of all groups decreased the emotional significance of the event, which made it possible to move away from the non-resource experience of an obstacle, the tendency to attack the source of frustration decreased, and the tendency to the fixation on satisfying a need increased.

\section{Discussions}

As a result of the study of the personality and reflection features of university students from conflict, postconflict and border regions, we came to the conclusion that there are interdependencies between the severity of these components and the external conditions of the region of residence, especially in such indicators as the reflection of the components of interpersonal interaction, susceptibility to an emotional response in a situation of frustration, a tendency to addictive behavior. Internal subjective indicators have been found that can predetermine low tolerance to frustration, low reflection and a tendency to sensitivity and dependence. Strengthening reflection contributes to an increase in the range of variability of personal properties and the expansion of boundaries, within the framework of such characteristics as "aggressiveness-anxiety," "spontaneity-sensitivity," "extroversion (outward orientation) - introversion (individualism)".

Failingly expressed leading trends within the indicated polarities can significantly change their intensity towards adaptability, due to which "depreciation" is carried out, mitigating the difficulties of adapting students to the traumatic living conditions in regions with different post-conflict status.

\section{Conclusion}

It is proved that reflexive game allows you to balance the balance between all types of reflection, increase the ability of students to go beyond the limits of their own "I", comprehend, study, analyze the course of events regarding the present, past and future. Restoring the balance between the types of reflection allows 
you to internally consider all hypotheses, make informed decisions, and calculate various options for the development of action.

It has been found that reflexive game helps to increase the overall reflexivity of thinking in the collective solution of tasks, develops strategies for cooperation and tolerance towards the opinions of others, and promotes the development of self-criticism and the collectivist approach as a whole.

It is confirmed that reflexive game significantly increases the level of awareness and responsibility among students, reduces emotional stress about experiencing frustration, and gives a new constructive experience in responding to situations of extremism. This is achieved due to the most adequate (constructive) type of response, which is characterized by a high reflection of the situation and its position in this situation, a tendency to assess the behavior of people on both sides of the conflict, accompanied by included attention and increased observation.

\section{References}

Abakumova, I.V., \& Ermakova, P.N. (2013). Psychology of the formation of anti-terrorism values of students of a modern university: textbook. Moscow: CREDO.

Anisimov, O.S. (1996). Methodology: function, essence, formation (dynamics and connection of times). Moscow: LMA.

Babiyants, K.A. (2011). Research and psychocorrectional capabilities of the methodology for eliminating the causes and growth factors of extremism in the youth environment. Psychology at the University, 5, 23-42.

Beitel, M., Ferrer, E., \& Cecero, J.J. (2004). Psychological mindedness and cognitive style. Journal of Clinical Psychology, 60(6), 567-582.

Fenigstein, A. (1997). Self-consciousness and its relation to psychological mindedness. Mahwah: Lawrence Erlbaum Associates Publishers.

Grant, A.M. (2001). Rethinking psychological mindedness: Metacognition, self-reflection and insight. Behaviour Change, 18(1), 8-17.

Karpov, A.V., \& Ponomareva, V.V. (2000). Psychology of reflexive control mechanisms. Moscow: Institute of Psychology RAS. 
Karpov, A.V., \& Skityaeva, I.M. (2005). Psychology of metacognitive processes of personality. Moscow: Publishing House "Institute of Psychology RAS".

Khadzharov, M.Kh. (2011). Sociology of confessional-cultural relations: tolerance as the basis for a dialogue of religious consciousness. Bulletin of Orenburg State University, 7(126), 144-151.

Krotov, D.V. (2009) Extremism and interethnic relations in the youth environment of Russia. Reference and methodological materials. Rostov-on-Don: North Caucasus National Center of the Southern Federal University.

Langer, E.J. (1978). Rethinking the role of thought in social interaction. New directions in attribution research, 2(1), 35-58.

Lefebvre, V.A. (2003). Reflection. Moscow: Kogit-Center.

Leontiev, D.A., \& Averina, A.Zh. (2011).vThe phenomenon of reflection in the context of the problem of self-regulation. Retrieved from http://psystudy.ru/index.php/eng/2011n2-16/476-leontievaverina16e.html

Manuylova, O.V. (2015). Methodological aspects of psychological reflection in the problems of antiextremist and antiterrorism orientation. North Caucasian Psychological Bulletin, 13(2), 46-52.

Ponomarev, Y.A., Semenov, I.N., \& Stepanov, S.Yu. (1986). Reflection in the development of creative thinking. Psychological journal, 6, 158-159.

Pyankova, G.S. (2012). Personal and professional reflection: a psychological workshop. Krasnoyarsk: Krasnoyarsk State Pedagogical University of V.P. Astafieva.

Rubinstein, S.L. (2003). Being and consciousness, man and the world. St. Petersburg: Peter Print.

Semenov, I.N. (2005). Reflective psychology of creativity: Concepts, experimentation, practice. Psychology: ST. Higher school economics, 2(4), 63-73.

Semenov, I.N., Davydov, G.I., \& Boldin, T.G. (2003). Reflexive-organizational aspects of the formation of thinking and personality in education and management. Moscow: ST. Higher school economics.

Sikevich, Z.V. (2003). Ethno-social background of extremism, extremism among St. Petersburg youth: analysis and prevention issues. St. Petersburg: Peter Print. 
Sobchik, L.N. (2017). Criminal tendencies and psychological testing. Psychology and Law, 7(1), 131-143.

Stepanov, S.Yu. (2000). Reflective practice of creative development of a person and organizations. Moscow: Nauka.

Tulviste, T. (1984). Origin of reflection in thinking: a review of studies on child and intercultural psychology. Tartu: TSU.

Usheva, T.F. (2007). Conditions for the formation of reflection of students of a pedagogical university. Higher education today, 10, 42- 44.

Znakov, V.V., \& Turok, E.M. (2010). Understanding and experiencing the terrorist threat. Bulletin of Moscow University, 1, 58-59. 